\title{
CASE REPORT \& REVIEW OF LITERATURE
}

\section{STRANGULATED LITTRE'S HERNIA: CASE REPORT AND REVIEW OF LITERATURE}

S. M. Datey, Ajay Lunawat, Avinash Vishwani, Rishikant Vashistha, Akshay Sharma

\footnotetext{
1. Professor. Department of General Surgery Sri Aurobindo Medical College and Postgraduate Institute, Indore, Madhya Pradesh.

2. Associate Professor. Department of General Surgery Sri Aurobindo Medical College and Postgraduate Institute, Indore, Madhya Pradesh.

3. Assistant Professor. Department of General Surgery Sri Aurobindo Medical College and Postgraduate Institute, Madhya Pradesh.

4. Assistant Professor. Department of General Surgery Sri Aurobindo Medical College and Postgraduate Institute, Indore, Madhya Pradesh.

5. Resident. Department of General Surgery Sri Aurobindo Medical College and Postgraduate Institute, Indore, Madhya Pradesh.
}

\section{CORRESPONDING AUTHOR:}

Dr. Sanjay M. Datey, Manushree, 43, Chikitsak Nagar,

Near Bombay Hospital, Indore (M.P.), India- 452010.

E-mail: sanjaymdatey@hotmail.com

ABSTRACT: Littre's hernia is uncommon clinical entity. We are presenting a case of Strangulated Littre's Hernia. A 19 years old male, came with pain and swelling in right inguinal region, which turned out to be an obstructed inguinal hernia with gangrenous Meckel's diverticulum. Gangrenous Meckel's diverticulum was resected and anastomosis of ileum was done. Hernial defect was repaired.

Detailed review of literature reveals that although Meckel's diverticulum is the most prevalent congenital anomaly of the gastrointestinal tract, and hernias are also common, but a Strangulated Littre's Hernia (where a Meckel's diverticulum is the content of a hernial sac) is very uncommon.

INTRODUCTION: We are reporting a case of a Strangulated Littre's hernia in a 19 year old male from Sri Aurobindo Medical College and Postgraduate Institute of Indore which is a leading tertiary care centre of Central India.

Detailed review of literature depicts that strangulation of a Meckel's diverticulum in an incarcerated hernia is uncommon. Cases have been reported sporadically in the literature, where a Meckel's diverticulum was found in the sacs of paraumbilical, femoral, inguinal, and incisional hernias. We are presenting this case of clinical interest, as it is uncommon.

Meckel's diverticulum is found in $2 \%$ of population, making it the most prevalent congenital abnormality of the gastrointestinal tract (Ref.1). Hernias are common. There is a rare possibility of Meckel's diverticulum becoming a content of hernial sac. That is why Littre's hernia is so uncommon and very few cases are reported. A Littre's hernia is seen in inguinal hernia(50\%), umbilical hernia (20\%),femoral hernia(20\%) and other hernias (10\%) (Ref. 2).

Presence of Meckel's diverticulum and its involvement in the pathological process can not be diagnosed by clinical examination. Almost all cases of Meckel's diverticulum are diagnosed on exploration in operation. Resection of an incidentally diagnosed Meckel's diverticulum is a controversial subject. Resection of a Meckel's diverticulum should be 


\section{CASE REPORT \& REVIEW OF LITERATURE}

recommended if there is no peritonitis due to other intraabdominal pathology. It has been described that Meckel's diverticulum has a $4 \%$ to $6 \%$ lifetime risk of developing a complication like bleeding, intussusception, obstruction, or perforation. (Ref. 3).

CASE REPORT: A Nineteen year old male presented to the emergency department of Sri Aurobindo Medical College and Postgraduate Institute, with complaints of a swelling and pain of abrupt onset in right groin, of two days duration. He also had mild fever and four loose motions on the previous day. He did not have any history of vomiting. There was a previous history of right inguinal swelling which used to appear on exertion for last 3 to 4 years. Patient did not have any trauma or recent infection of right lower limb or genitalia which could have lead to inguinal lymphadenitis.

On admission, he was stable haemodynamically and no abnormality could be detected on general and systemic examination of patient. On local examination of right groin, there was a tender swelling of $3 \times 4 \mathrm{~cm}$. in the region of inguinal canal with raised local temperature. There was no cough impulse in the swelling. Clinical diagnosis of an incarcerated inguinal hernia with probable strangulation of its contents was made.

Preoperative hematological and biochemical investigations were done. Except for a polymorphonuclear leucocytosis, all other reports were within normal limits. Urgent operation for exploration of right inguinal canal was planned. Operation was done under general anesthesia. On exploration a Strangulated Meckel's diverticulum was found in the sac of an obstructed indirect inguinal hernia. Deep inguinal ring was cut laterally and the obstructing ring was released. The ileal loops were delivered in the wound to exclude any abnormality . As the Meckel's diverticulum was broad based and gangrenous upto its junction with the ileum, a decision to perform resection of Meckel's diverticulum with part of ileum was taken. Resection was done and continuity of ileum restored by an end to end anastomosis .Anastomosed loop of the bowel was reposited and peritoneum closed. Repair of the posterior wall of inguinal canal was done by herniorrhaphy. Patient had an uneventful postoperative recovery .He was discharged from the hospital after a week in a satisfactory condition.

DISCUSSION AND REVIEW OF LITERATURE: Littre's hernia is defined as the protrusion of Meckel's diverticulum through a potential abdominal opening.(Ref.2) Littre's hernia is uncommon, and a detailed review of literature revealed that very few cases of a Strangulated Littre's Hernia have been reported so far.

Our patient had atypical presentation as although he presented with usual symptoms of pain, swelling and previous history of a swelling of groin appearing on exertion, but he had one unusual symptom of loose motions. This increase in the frequency of bowel movements could be attributed to partial occlusion of intestinal lumen(as occurs in a Ritcher's hernia) leading to irritation and inflammation of bowel. The symptom of loose motion could be misleading and can cause a dangerous delay in the diagnosis of an incarcerated hernia.

Contents of a hernial sac like Meckel's diverticulum (Littre's hernia), Appendix Vermiformis (Amayand's hernia), partial lumen of intestine (Ritcher's hernia), ovary or a fallopian tube can not be diagnosed by clinical examination. Computerised tomography could have diagnosed it preoperatively but this investigation is not done routinely in all patients.

Meckel's diverticulum was described by German Professor John Fredriche Meckel in 1809 as an ileal diverticulum present in $2 \%$ of population on the antimesenteric border. It is usually located 30 to $90 \mathrm{~cm}$. from the ileocaecal junction, measuring 3 to $6 \mathrm{~cm}$ in length and $2 \mathrm{~cm}$ 


\section{CASE REPORT \& REVIEW OF LITERATURE}

in diameter. Meckel's diverticulum is a true diverticulum and represents the persistent part of the omphalomesenteric duct through which the midgut communicates with umbilicus till the fifth week of intrauterine life.

Meckel's diverticulum can cause life threatening complications. Diverticulitis can lead to severe peritonitis due to perforation. It can be a source of gastrointestinal hemorrhage. Meckel's diverticulum can get adhered to parietal peritoneum or go into a hernial sac and act as a fixed point for a volvulus.

Park JJ et al (Ref 4) from the Mayo clinic have published the results of a retrospective study of 1476 patients of Meckel's diverticulum between 1950 and 2002. This study is the most comprehensive work available on the subject of Meckel's diverticulum. Out of 1476 patients, only two had incarceration of Meckel's diverticulum in a hernial sac over a period of 52 years(1950-2002) in the case series of Mayo Clinic. The study was done by Park JJ et al to find out which Meckel's diverticulum should be removed if found incidentally in the course of an abdominal operation .They observed that in today's surgical practice it is safe to remove all the incidentally detected Meckel's diverticula, but it can not be made a rule. Mayo clinic study by Park JJ et al further states that "they neither support nor reject the recommendation of excising all the incidental Meckel's diverticula". Sixteen percent of these 1476 patients had symptomatic Meckel's diverticulum. These patients had their abdominal problems due to Meckel's diverticulum like gastrointestinal hemorrhage, intestinal obstruction, intussusception, diverticulitis or perforation .Certain features in these $16 \%$ patients were common, namely, the male sex, age was less than 50 years and length of diverticulum was more than $2 \mathrm{~cm}$. Thus it can be said that an incidentally detected Meckel's diverticulum of more than $2 \mathrm{~cm}$ in young males should always be removed.

Alexis de Littre (1700), A French anatomist and physician was the first to describe a protrusion of ileal diverticulum in an inguinal hernia .He postulated it to be a traction diverticulum of ileum. Zungia et al (Ref 5) said that the true incidence is difficult to estimate because Littre's hernias are uncommon. Incarceration and strangulation of Meckel's diverticulum in inguinal hernias have been reported in two cases by Cirillo et al (Ref 6) and Mongardini et al (Ref 7).Cases of strangulated Meckel's diverticulum in a hernial sac have been reported by Albert Tiu et al (Ref 8) in a Paraumbilical hernia, Perlman JA et al (Ref 9) in a femoral hernia , Citgez b et al (Ref 9) in a Ventral incisional hernia and Castleden WM et al (Ref 10) in an Umbilical hernia. Preoperative diagnosis of a Meckel's diverticulum was not possible in any of the reported cases. The diagnosis was established on opening the sac and resection of Meckel's diverticulum was done in all the cases with uneventful recovery .

Sinha et al (Ref 11) reported a case of Littre's hernia causing an intestinal obstruction , which was diagnosed by computerised tomography. With the increased use of computerised tomography in the diagnosis of acute abdominal conditions more cases will be diagnosed preoperatively.

Review of literature and this case report shows that Meckel's diverticulum can be safely resected with repair of hernias . Multiple pathologies encountered in the course of an abdominal operation should be dealt with on its own merits and established principles of surgical treatment.

ACKNOWLEDGMENT: We are thankful to Dr.Vinod Bhandari, Chairman, Sri Aurobindo Medical College and Postgraduate Institute, Dean Dr.S.D.Joshi and Dr. P.K.Banerjee, Professor and Head of Department of Surgery for the permission to publish this case report. 


\section{REFERENCES:}

1.Williams RS: Management of Meckel's diverticulum ; Br J Surg 1981, 68:477-480.

2.Skandalakis PN, Zoras O, Skandalakis JE, Mirilas P: Littre Hernia; Surgical Anatomy, embryology, technique of repair ; Am Surg 2006 Mar ;72(3) :238-43.

3.Evangelos Zachakaris MD, Vasilios Papadopolos MD, Thanos Athaasiou MD,PHD,FECTS, Paul Ziprin MD,FRCS, Emmanouil Zachakaris MD,PHD : An unusual presentation of Meckel's diverticulum in a strangulated femoral hernia; South Med J 2008; 101(1) :96-98.

4.Park JJ, Wolff BG, Tollefson MK et al: Meckel's Diverticulum;The Mayo Clinic experience with 1476 patients (1950-2002) Am Surg :2005;241: 529-533.

5.Zungia D, Zupanee R : Littre hernia ; JAMA 1997 ;237 :1599-1600.

6.Cirillo F, Troiano L, Mortini B, Agarossi M, Riboldi 0 :An inguinal hernia with strangulated Meckel's diverticulum ( Littre's hernia) ; A Case report and review of literature ; Minnerva chir :1991 Jun 15:46(11):627-630.

7.Mongardini M, Merlino P, Schillaci F, Cola A, Blasi S, Fanello G,Benedetti F, Maturo A, Pappalardo G : Gangrene of Meckel's diverticulum in strangulated left inguinal hernia (Article in Italian) ; G Chir 2005, oct; 26(10) : 384-6.

8.Albert Tiu, Dominic Lee: An unusual manifestation of Meckel's Diverticulum : Strangulated paraumbilical hernia :NZMJ (23 June) 2006, Vol 119,No.1236.

9. Perlman JA, Hoover HC,Safer PK : Femoral hernia with strangulated Meckel's diverticulum (Littre's Hernia):Case report with review of literature: Am J Gastroenterol 1980;139:286289.

10. Castelden WM : Meckel's diverticulum in a umbilical hernia : Br J Surg $1970 ; 57$ :932934.

11. Sinha R : Bowel obstruction due to Littre's Hernia :CT Diagnosis : Abdom Imaging ;2005 Nov-Dec; 30(6) :682-4.

OPERATIVE PHOTOGRAPH: Showing exposure of right inguinal canal with Gangrenous Meckel's Diverticulum with loop of ileum.

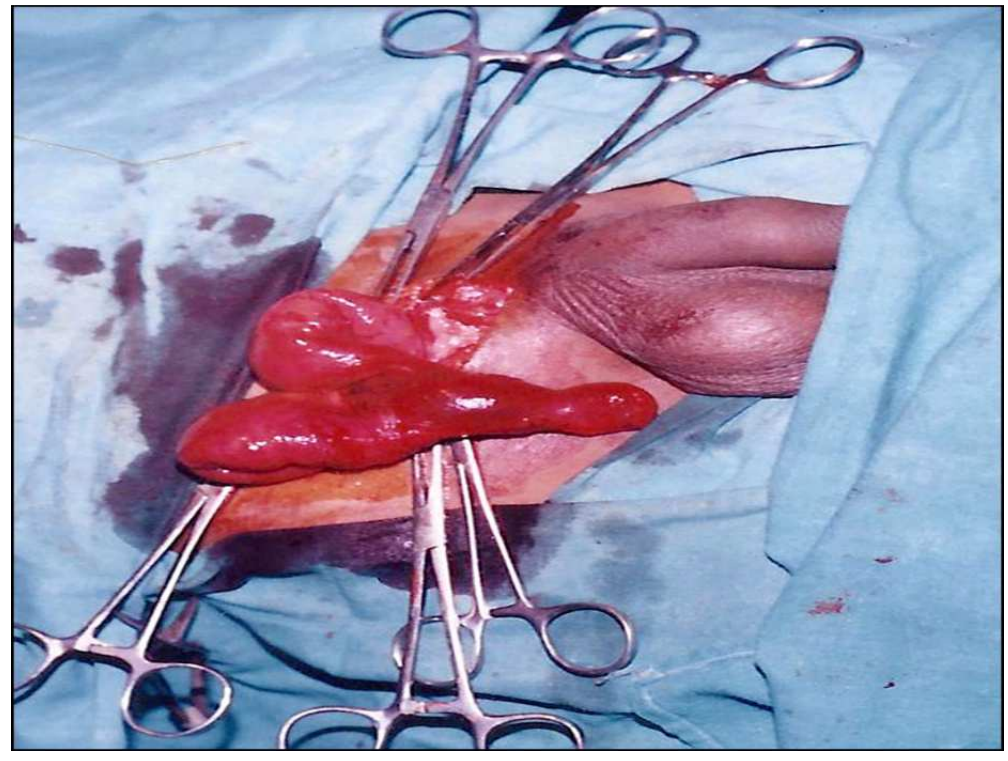

